\title{
REVIEW
}

\section{Social Inequality and Diabetes: A Commentary}

Katharine D. Barnard-Kelly · Daniel Cherñavvsky

Received: December 5, 2019 / Published online: March 2, 2020

(C) The Author(s) 2020

\section{ABSTRACT}

Socioeconomic inequality of access to healthcare is seen across the spectrum of healthcare, including diabetes. Health inequalities are defined as the 'preventable, unfair and unjust differences in health status between groups, populations or individuals that arise from the unequal distribution of social, environmental and economic conditions within societies, which determine the risk of people getting ill, their ability to prevent sickness or opportunities to take action and access treatment when ill health occurs' (NHS England; https://www. england.nhs.uk/about/equality/equality-hub/re sources/). Access to diabetes technologies has

Enhanced digital features To view enhanced digital features for this article go to https://doi.org/10.6084/ m9.figshare.11733972.

K. D. Barnard-Kelly $(\square)$

Faculty of Health and Social Science, Bournemouth

University, Bournemouth, UK

e-mail: katharinebarnard@bhrltd.com

D. Cherñavvsky

Dexcom, Inc, San Diego, CA, USA

D. Cherñavvsky

University of Virginia, Charlottesville, VA, USA improved glycaemic and quality-of-life outcomes for many users. Inability to access such devices, however, is evidenced in National Diabetes Audit data, with a reported tenfold variation in insulin pump use by people with type 1 diabetes across specialist centres. This variation suggests a lack of access to healthcare systems that should be investigated. This article highlights some of the key issues surrounding healthcare inequalities in the management of diabetes.

Keywords: Diabetes; Diabetes technologies; Glycaemic control; Social deprivation; Social inequality 
Infographic

\section{DiabetesTherapy $7.7 \mathrm{OPEN}$}

\section{Social Inequality and Diabetes: A Commentary}

Cite this article as: Barnard-Kelly, K. \& Cherñavvsky, D. Diabetes Ther (2020). https://doi.org/10.1007/s13300-020-00791-4

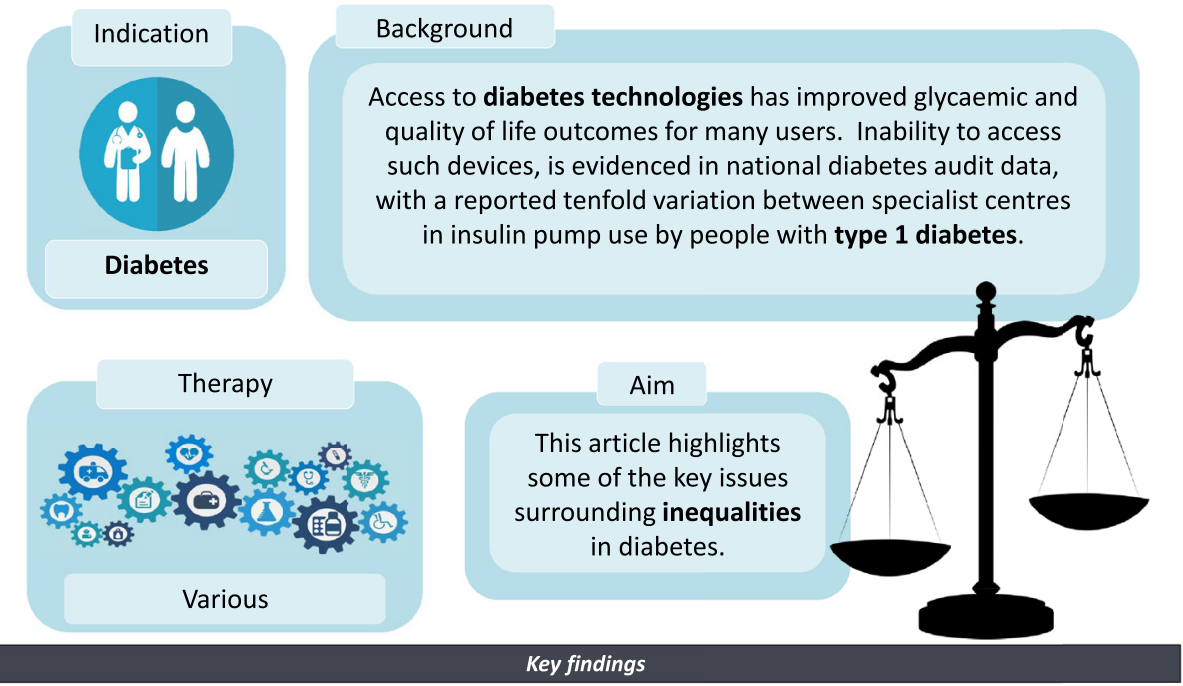

Socio-economic inequalities in health and associated risk factors are well reported. Those at highest need are least likely to receive healthcare.

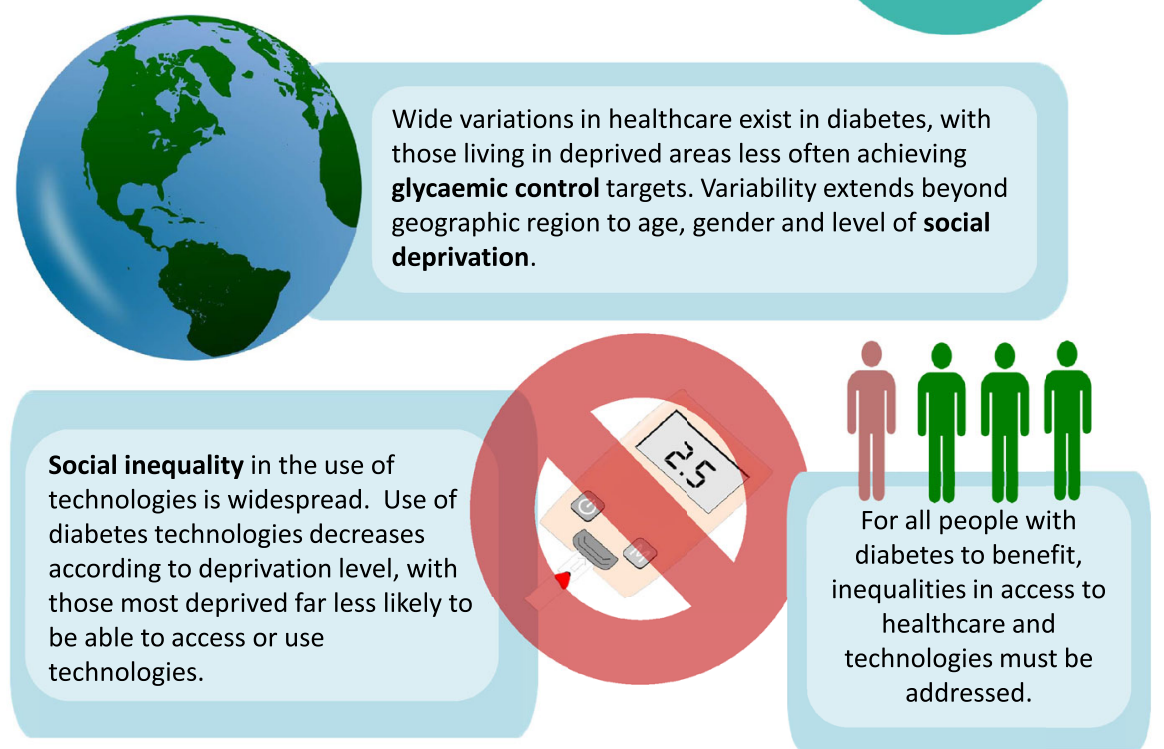

\section{$\triangle$ Adis}




\section{SOCIOECONOMIC INEQUALITIES AND ACCESS TO HEALTHCARE}

Socioeconomic inequalities in health and associated risk factors are well known [1]. Those at highest need are reported to be the least likely to receive healthcare, a phenomenon known as Hart's inverse care law [2]. A further issue is the recognition that individual 'agency', i.e. selfdeterministic interventions, may widen inequalities as disadvantaged groups are less likely to participate [3]. Socioeconomic inequality of access to healthcare is seen across the entire spectrum of healthcare, not just in diabetes [4]. Data from non-emergency coronary revascularisation procedures in the National Health Service (NHS) showed substantive differences in waiting times of up to $35 \%$ (or 43 days) within public hospitals between those in the most and least deprived population quintile groups. Individuals in the least deprived group benefit from shorter waiting times and associated health benefits worth up to $£ 850$ per person [4].

Such inequality is not restricted to the UK, and the widening economic inequality in the USA has been accompanied by increasing disparities in health outcomes [5]. According to Dickman et al. [5], the life expectancy of the wealthiest Americans now exceeds that of the poorest by $10-15$ years. Focusing on diabetes in particular, Grintsova et al. performed a systematic review of studies on inequalities in healthcare among patients with type 2 diabetes (T2D) by individual socioeconomic status (SES) and regional deprivation [6]. Their results reveal the existence of clear inequalities, a wide variety of definitions for 'good quality diabetes care', regional deprivation and individual SES. These authors reported that despite differences in research approaches, there was a trend towards worse healthcare for patients with low SES in terms of both process of care and intermediate outcome indicators. Patients living in deprived areas less often achieved glycaemic control targets and tended to have high blood pressure and worse lipid profile control. The authors concluded that low individual SES and residential area deprivation were associated with higher risks of microvascular and macrovascular complications and existed across different healthcare systems [6]. Moreover, the situation of health inequality was exacerbated in the last decade due to the world recession of 2008 [7], following which it was reported that more health issues-diabetes in particular-started to be seen in younger population with low socioeconomic background.

Health inequalities are defined by NHS England and Public Health England as the preventable, unfair and unjust differences in health status between groups, populations or individuals that arise from the unequal distribution of social, environmental and economic conditions with societies, which determine the risk of people getting ill, their ability to prevent sickness, or opportunities to take action and access treatment when ill health occurs' [8]. In the UK, the Health and Social Care Act 2012 required health bodies to have due regard to reducing health inequalities [9], and the passing of the Social Value Act 2012 [10] further required local authorities and health sector bodies (in England) to consider 'economic, social and environmental wellbeing in procurement of services for contracts'. Pre-dating both of these public health policies, however, was the Equalities Act 2010 [11] which aimed to protect people from discrimination in the workplace and in wider society. It could be argued, almost a decade later, that the persistent failure to effectively address inequalities in healthcare provision, access to appropriate therapies and education delivered in ways that meet the needs of diverse populations breaches this legislation, with inequalities clearly continuing to exist.

This article is based on previously conducted studies and does not contain any studies with human participants or animals performed by any of the authors.

\section{EXISTENCE OF SOCIOECONOMIC INEQUALITY IN DIABETES CARE}

It is well known that there is considerable variation in the delivery of diabetes care processes, structured education on diabetes, uptake of diabetes technologies and achievement of 
Table 1 Variability in delivery of care processes and achievement of targets in diabetes management

\begin{tabular}{|c|c|c|c|c|}
\hline \multirow[t]{2}{*}{ Care process/target } & \multicolumn{2}{|c|}{ Type 1 diabetes mellitus } & \multicolumn{2}{|c|}{ Type 2 diabetes mellitus } \\
\hline & $\begin{array}{l}\text { Most deprived } \\
\text { (\%) }\end{array}$ & $\begin{array}{l}\text { Least deprived } \\
\text { (\%) }\end{array}$ & $\begin{array}{l}\text { Most deprived } \\
\text { (\%) }\end{array}$ & $\begin{array}{l}\text { Least deprived } \\
\text { (\%) }\end{array}$ \\
\hline Received all eight care processes ${ }^{a}$ & 39.0 & 45.1 & 55.8 & 61.8 \\
\hline $\begin{array}{l}\text { Met treatment targets of } \mathrm{HbAlc} \text {, blood pressure } \\
\text { and cholesterol }\end{array}$ & 15.4 & 21.9 & 38.6 & 41.2 \\
\hline
\end{tabular}

HbAlc Glycated haemoglobin

a Body mass index measurement, blood pressure measurement, HbAlc measurement, cholesterol measurement, record of smoking status, foot examination, albumin:creatinine ratio, serum creatinine measurement

diabetes-related targets [12]. This variability extends beyond geographic area, with inequalities also reflected across age, gender and level of social deprivation. Those in the most deprived quintile are less likely to receive all eight care processes recommended by the National Institute for Health and Care Excellence (NICE) (see footnote to Table 1) than those in the least deprive quintile [type 1 diabetes (T1D) 39.0 vs. $45.1 \%$; T2D 55.8 vs. $61.8 \%$ ] or to meet all three treatment targets of glycated haemoglobin (HbA1c), blood pressure and cholesterol (see Table 1.

\section{RELATIONSHIP BETWEEN SOCIOECONOMIC INEQUALITY AND ACCESS TO DIABETES CARE}

Based on data from 2016 to 2017, the National Diabetes Insulin Pump Audit reported that the 'tenfold variation between specialist centres in pump use by people with T1D suggests a lack of access for patients attending some services and should be investigated' [13]. Pump treatment is more often seen among younger people with T1D, with $25.9 \%$ of those under 30 years of age using an insulin pump compared to only $8.9 \%$ of those aged 60-69 years [14]. Furthermore, there is a clear decrease in the number of people using pumps that is in line with increasing levels of deprivation, with $15 \%$ of those most deprived using an insulin pump compared to $24 \%$ of those least deprived [12]. These figures are mirrored in paediatric services, with $37.5 \%$ of those least deprived using pump therapy compared with $25.6 \%$ of those most deprived [15].

Adopting a broader approach to variability in diabetes care, Khunti et al. [16] reported that patients at primary care practices in deprived areas lag behind those in affluent areas in terms of access to members of the diabetes team. These authors recommend that the deficiencies and inequalities highlighted in their study must be addressed in order to improve the care of people with diabetes. Scottish data shows [17] a steep gradient in the prevalence of T2D across quintiles of deprivation (based on the Index of Multiple Deprivation), with those in the lowest quintile having a $77 \%$ increased odds of having T2D compared to those in the highest. Roper et al. [18] argues that a plausible interpretation of these data is that the greater vulnerabilities to T2D associated with more deprived areas lead to a higher incidence of T2DM in younger age groups, which in turn would contribute to increased risk cardiovascular disease and premature mortality.

In 2014, Haas et al. published the US National Standards for Diabetes Self-Management Education and Support in which it is argued that 'diabetes self-management education is a critical element of care for all people with diabetes and those at risk of developing the disease' [19]. Standard Seven of these US National Standards is entitled 'Individualisation' and calls for the needs of each participant to be assessed by one or more instructors. The participant and instructor(s) will then together develop an individualised education and support plan focused on behaviour change. The 
National Standards further state that the assessment must garner information about the individual's medical history, age, cultural influences, health beliefs and attitudes, diabetes knowledge, diabetes self-management skills and behaviours, emotional response to diabetes, readiness to learn, literacy level (including health literacy and numeracy), physical limitations, family support, and financial status', citing several articles as evidence of these as important factors affecting diabetes self-management [19].

It is somewhat disheartening, therefore, that in the UK in 2016 only $37.8 \%$ of people diagnosed with T1D were offered structured education, of whom only $4.3 \%$ actually attended these educational sessions [12]. These figures have been consistently poor year-on-year since 2013. For people diagnosed with T2D, the figures are significantly better, with $74.5 \%$ of people diagnosed with T2D offered structured education in 2016 , although only $8.3 \%$ attended the educational sessions [12]. There are several factors potentially contributing to such low uptake, although the standardised models of structured education in the UK have been often criticised for their lack of diversity.

Further evidence of inequalities in diabetes outcomes comes in the form of a systematic review by Lindner et al. in 2018 [20]. These authors examined the associations of individual level as well as area-level SES and area-level deprivation with glycaemic control, hypoglycaemia and diabetic ketoacidosis in people with T1D. Twenty studies were included in the analysis, but most were of average quality. The results are contradictory in terms of associations of SES and area-level deprivation with glycaemic control and hypoglycaemia, but they do show that lower SES and higher area-level deprivation are associated with a high risk of experiencing diabetic ketoacidosis. Based on these findings, the authors recommended that access to care for socially deprived people needs to be expanded to overcome impairing effects on the course of the condition and to reduce healthcare disparities [20].

Undiagnosed diabetes and impaired glucose regulation fare no better. Moody et al. [21] conducted five annual cross-sectional health examination surveys in a random selection of private homes across England between 2009 and 2013. The first stage was a health interview, including questions about diagnosed conditions, self-rated health and measured height and weight; the second stage was a nurse visit, which included taking further physical measurements, recording prescribed medication(s) and collecting biological samples. All adults in the selected households were eligible for interview, and all interviewed participants were eligible for the nurse visit and biological sampling [21]. In most years, around 8000 adults participated in an interview and around 6000 had a nurse visit; all data collection occurred in the participant's own home. The results showed that $11 \%$ of the participants had impaired glucose regulation (IGR), $2 \%$ had undiagnosed diabetes and 6\% had diagnosed diabetes; age standardised prevalence was highest among Asian $\{19 \%$ [95\% confidence interval (CI) 16-23\%], 3\% (95\% CI 2-5\%) and 12\% (95\% CI 9-16\%), respectively\} and black participants [17\% (95\% CI 13-21\%), 2\% (95\% CI $1-4 \%$ ) and $14 \%$ (95\% CI 9-20\%), respectively]. These were also higher among people with lower income and less education, those of a lower occupational class and those with greater deprivation. Multivariate regression analysis revealed that education [odds ratio (OR) 1.49 (95\% CI 1.27-1.74) for no qualifications vs. degree or higher] and income [OR 1.35 (95\% CI 1.12-1.62) for lowest vs. highest income quintile] remained significantly associated with IGR or undiagnosed diabetes [21]. The authors concluded that social inequalities in hyperglycaemia management do exist, in additional to well-known demographic and anthropometric risk factors for diabetes and IGR.

\section{Addressing Healthcare Access}

In 2019 Choudhary et al. published an article entitled 'A type 1 diabetes technology pathway: consensus statement for the use of technology in type 1 diabetes' [22]. This consensus of expert views, in collaboration with NHS England and Diabetes UK, recognised that while NICE 
recommended some diabetes technologies, others have not been appraised, and new technologies are emerging all the time. The different guidelines for adults and children add still further to the confusion, particularly complicating access to technologies in the transition from paediatric to adult care. The pathway supports the incremental addition of technology as monotherapy and then dual therapy in the same way that therapeutic agents are added to support people with T2D in order to achieve their personalised glycaemic targets. The pathway emphasises the importance of structured education, specialist support and appropriate access to psychological therapies as essential pillars for optimised use of diabetes-related technology-however, there is no mention of the lack of psychological therapies available in adult services. The pathway was based on the existing model of the American Diabetes Association/European Association for the Study of Diabetes guidelines for T2D that set out a roadmap for the incremental escalation of treatment to try and support patients to achieve their individualised glycaemic goal.

\section{Potential Solutions}

The use of new technology has been proven to be beneficial, particularly so in rural and less wealthy areas where telemedicine has been used for neurological diseases [23] and diabetes [24]. With this in mind, we believe that improving access to technology in poor areas could level the playing field for healthcare disparities. This should be done with a clear plan to ensure that it is sustainable over time to be effective. Such a plan should include and start with training curricula for health sciences students and providers and by making technology accessible to underserved areas in a way that is financially supported.

A study by Gimenez-Perez et al. [25] concluded that the benefit of new technologies, communication technologies in particular, can be jeopardized in people with T1D by the low rate of access and utilization. Were people to have greater access to technology it is possible to infer that the treatment and management of diabetes would potentially improve [26]. T1D is a complex chronic disease, and those from underserved areas suffer from a lack of access to healthcare or to the emerging technologies to treat and relieve the burden of disease, not only for the person with T1D but also for his/her family [27]. Research conducted by the Pew Research Center [28] shows that the vast majority of the US population have access to a cell phone (96\%), with $81 \%$ having a smartphone. This has increased convenience and access to health technologies for many; for example, continuous glucose monitoring via an app, with the activity and values being reported and transmitted to the healthcare provider, who can then in turn interact with the specific patient. Cell phones increasingly play a role in the way healthcare is accessed and delivered. As such, universities and researchers are increasingly including the relationship between geographical habitat and patient care in their curricula as such physical barriers are overcome. This novel approach could equip healthcare providers with novel contributions to reduce socioeconomic differences and improve equality when providing the right of health [29].

All reasonable efforts must be employed to ensure broad access to such technologies, not least because it must be remembered that the benefits are restricted to those with both access to and a desire to use smartphones or other means to access the internet for health purposes. Highlighting the benefits of using innovative approaches to overcome health literacy challenges and improving the user interface while ensuring evidence-based, theory-driven foundations will enable users to have trust in novel technologies as they increasingly access them.

\section{DISCUSSION AND CONCLUSION}

The challenges of socioeconomic inequality and healthcare, particularly in the context of diabetes and technologies, are undoubtedly complex, and there is unlikely to be a one-size-fitsall solution. The aim to reduce health inequalities and the aim to improve the outcomes of the most deprived are distinct goals and, 
therefore, both must be considered. Multimorbidity, for example, affects both the elderly and those who are more deprived. This is compounded by the fact that diabetes is itself associated with a greater risk of multi-morbidity. Those with multiple chronic conditions face substantial challenges in maintaining a range of treatment regimes, and so we might expect issues with utilisation and successful usage of treatments and therapies irrespective of SES.

Furthermore, the risk factors for T2D must be considered in the context of socioeconomic inequality; for example, lifestyle factors such as obesity, self-reported physical activity, smoking status and self-reported consumption of fresh fruit and vegetables are all lower in adults in the poorest households. Those in the lowest socioeconomic quintile have a $77 \%$ increased odds of having T2DM than those in the highest quintile [18]. Successful preventive approaches, such as the Diabetes Prevention Program, specifically targets people living in deprived areas and protected groups such as Black, Asian and minority populations.

The role of area-level deprivation versus individual SES should be considered. Area-level data are based on census data; as such, data on housing, employment, social class and availability of cars are used to create a single measure of how deprived an area is. Although such global data can mask the variability in individual SES, area-level data are often used as a proxy measure of individual SES. The allocation of resources based on deprivation indices must ensure the resource needs of healthcare providers, particularly as those in deprived areas often have higher workloads and are more resource intensive.

Different studies and real-world evidence have shown that the results of treatment for diabetes, in particular T1D, remains the same from early childhood to elderly adults as expressed in average HbA1c plots [30], with lower treatment efficacy during adolescence and young adults. There is no doubt that SES influences poor control at all ages, as assessed by a recent analysis of data gathered by the T1D Exchange [31].

In conclusion, lower SES is clearly associated with poor outcomes of and poorer compliance with diabetes treatment. The new advances in diabetes technology combined with making these accessible to all, but in particular to the lower SES population, can remedy this issue. In addition, the outreach of media devices, such as cellphones, for use in telemedicine could also contribute to levelling the field treatment-wise since the penetration of digital devices is increasing exponentially in all socioeconomical and sociocultural levels [32-34].

\section{ACKNOWLEDGEMENTS}

Funding. No funding or sponsorship was received for this study or publication of this article.

Authorship. All named authors meet the International Committee of Medical Journal Editors (ICMJE) criteria for authorship for this article, take responsibility for the integrity of the work as a whole, and have given their approval for this version to be published.

Disclosures. Katharine Barnard-Kelly has received research funding from Novo Nordisk, $\mathrm{BD}$, Roche Diabetes Care and consultancy fees from Roche Diabetes Care, Sanofi. Daniel Cherñavvsky is a full-time employee of Dexcom, Inc.

Compliance with Ethics Guidelines. This article is based on previously conducted studies and does not contain any studies with human participants or animals performed by any of the authors.

Open Access. This article is licensed under a Creative Commons Attribution-NonCommercial 4.0 International License, which permits any non-commercial use, sharing, adaptation, distribution and reproduction in any medium or format, as long as you give appropriate credit to the original author(s) and the source, provide a link to the Creative Commons licence, and indicate if changes were made. The images or other third party material in this article are included in the article's Creative Commons 
licence, unless indicated otherwise in a credit line to the material. If material is not included in the article's Creative Commons licence and your intended use is not permitted by statutory regulation or exceeds the permitted use, you will need to obtain permission directly from the copyright holder. To view a copy of this licence, visit http://creativecommons.org/licenses/by$\mathrm{nc} / 4.0 /$.

\section{REFERENCES}

1. Marmot M, Goldblatt P. Importance of monitoring health inequalities. BMJ. 2013;347:f6576.

2. Hart JT. The inverse care law. Lancet. 1971;297(7696):405-12.

3. Gillett M, Royle P, Snaith A, et al. Non-pharmacological interventions to reduce the risk of diabetes in people with impaired glucose regulation: a systematic review and economic evaluation. Health Technol Assess. 2012;16(33):1-236.

4. Moscelli G, Siciliani L, Gutacker N, Cookson R. Socioeconomic inequality of access to healthcare: does choice explain the gradient? J Health Econ. 2018;57:290-314.

5. Dickman SL, Himmelstein DU, Woolhandler S. Inequality and the healthcare system in the USA. Lancet. 2017;389(10077):1431-41.

6. Grintsova $\mathrm{O}$, Maier $\mathrm{W}$, Mielck A. Inequalities in healthcare among patients with type diabetes by individual socio-economic status (SES) and regional deprivation: a systematic literature review. Int J Equity Health. 2014;13:43.

7. Casanova L, Carrier H, Martin de Vidales A, Cortaredona S, Verger P. Trends in social inequities in diabetes care in the Provence-Alpes-Côted'Azurregion of France between 2008 and 2011. Rev Epidemiol Sante Publique. 2017;65(1):29-40.

8. NHS England. Reducing health inequalities resources. 2019. https://www.england.nhs.uk/about/ equality/equality-hub/resources/. Accessed $30 \mathrm{Apr}$ 2019.

9. Health and Social Care Act 2012. 2012. https:// assets.publishing.service.gov.uk/government/uploa ds/system/uploads/attachment_data/file/138257/A1.Factsheet-Overview-240412.pdf. Accessed 30 Apr 2019.
10. The Public Services (Social Value) Act 2012. 2012. https://www.gov.uk/government/publications/soci al-value-act-introductory-guide. Accessed 26 Aug 2019.

11. Equality Act 2010. 2010. https://www.gov.uk/ guidance/equality-act-2010-guidance. Accessed 26 Aug 2019.

12. NHS Digital (Health and Social Care Information Centre). National Diabetes Audit Report 1: care processes and treatment targets, 2017-18. Government Statistical Service. 2018. https://digital.nhs. uk/data-and-information/publications/statistical/na tional-diabetes-audit/national-diabetes-audit-report1-care-processes-and-treatment-targets-2017-18. Accessed 15 Jan 2020.

13. NHS Digital (Health and Social Care Information Centre). National Diabetes Audit Report 1: care processes and treatment targets, 2016-17. Government Statistical Service. 2018. https://digital.nhs. uk/data-and-information/publications/statistical/na tional-diabetes-audit/national-diabetes-audit-report1-care-processes-and-treatment-targets-2016-17. Accessed 15 Jan 2020.

14. Barnard K. Exposure to diabetes technologies: where now for adult services? Medicine Matters. https:// diabetes.medicinematters.com/en-GB. Accessed 15 Jan 2020 .

15. National Paediatric Diabetes Audit 2016-17. https://www.rcpch.ac.uk/resources/npda-annualreports. Accessed 27 Feb 2020.

16. Khunti K, Ganguli S, Lowy A. Inequalities in provision of systematic care for patients with diabetes. Fam Pract. 2001;18:27-32.

17. Scottish Diabetes Survey Monitoring Group. Scottish Diabetes Survey 2008. Edinburgh: NHS Scotland; 2008.

18. Roper NA, et al. Excess mortality in a population with diabetes and the impact of material deprivation: longitudinal, population-based study. BMJ. 2001;322:1389-93.

19. Haas L, Maryniuk M, Beck J, et al. National standards for diabetes self-management education and support. Diabetes Care. 2014;37:S1.

20. Lindner LME, Rathmann W, Rosenbauer J. Inequalities in glycaemic control, hypoglycaemia and diabetic ketoacidosis according to socio-economic status and area-level deprivation in type 1 diabetes mellitus: a systematic review. Diabet Med. 2018;35(1):12-32.

21. Moody A, Cowley G, Ng Fat L, et al. Social inequalities in prevalence of diagnosed and 
undiagnosed diabetes and impaired glucose regulation in participants in the health surveys for England series. BMJ Open. 2016;6:e010155. https:// doi.org/10.1136/bmjopen-2015-010155.

22. Choudhary P, Campbell F, Joule N, et al. A type 1 diabetes technology pathway: consensus statement for the use of technology in type 1 diabetes. Diabet Med. 2019;36(5):531-8.

23. Dayal P, Chang CH, Benko WS, et al. Hospital utilization among rural children served by pediatric neurology telemedicine clinics. JAMA Netw Open. 2019;2(8):e199364.

24. Hartz J, Yingling L, Powell-Wiley TM. Use of mobile health technology in the prevention and management of diabetes mellitus. Curr Cradiol Rep. 2016;18(12):130.

25. Giménez-Pérez G, Gallach M, Acera E, et al. Evaluation of accessibility and use of new communication technologies in patients with type 1 diabetes mellitus. J Med Internet Res. 2002;4(3):e16.

26. Prahalad P, Tanenbaum M, Hood K, Maahs DM. Diabetes technology: improving care, improving patient-reported outcomes and preventing complications in young people with type 1 diabetes. Diabet Med. 2018;35(4):419-29.

27. Abdoli S, Hardy LR, Hall J. The complexities of "Struggling to Live Life": the experiences of young adults with T1DM living in appalachia. Diabetes Educ. 2017;43(2):206-15.

28. Pew Research Center. Mobile fact sheet. 2019. https:// www.pewinternet.org/fact-sheet/mobile/. Accessed 15 Jan 2020.
29. Blatt AJ, editor. Geospatial medicine. In: Health, science, and place. Geotechnologies and the environment, vol 1. 2015. Cham: Springer. https://doi. org/10.1007/978-3-319-12003-4.

30. Miller, et al. Diabetes Care. 2015;38:971-8. https:// doi.org/10.2337/dc15-0078.

31. Miller KM, Beck RW, Foster NC, Maahs DM. HbA1c levels in type 1 diabetes from early childhood to older adults: a deeper dive into the influence of technology and socio-economic status on HbA1c in the T1D exchange clinic registry findings. Diabetes Technol Ther. 2020. https://doi.org/10.1089/ dia2019.0393.

32. Anderson-Lewis C, et al. mmHealth technology use and implications in historically underserved and minority populations in the United States: systematic literature review. JMIR Mhealth Uhealth. 2018;6(6):e128. https://doi.org/10.2196/mhealth. 8383.

33. Hue J, Koola J, Contreras A, et al. Consumer health informatics adoption among underserved populations: thinking beyond the digital divide. Yearb Med Inform. 2018;27(1):146-55. https://doi.org/10. 1055/s-0038-1641217.

34. Deloitte Centre for Health Solutions. Connect health: how digital technology is transforming health and social care. 2020. https://www2.deloitte. com/content/dam/Deloitte/uk/Documents/life-scien ces-health-care/deloitte-uk-connected-health.pdf. Accessed 22 Jan 2020. 